\title{
POLÍticas de COMBATE À FOME NO BRASIL
}

\author{
WALTER BELIK \\ Professor do Instituto de Economia da Unicamp, Consultor da Fundação Seade \\ José Graziano da Silva \\ Professor do Instituto de Economia da Unicamp, Bolsista do CNPq, Consultor da Fundação Seade \\ MaYa TAKagi \\ Engenheira Agrônoma, Analista da Fundação Seade
}

\begin{abstract}
Resumo: Até os anos 30, os problemas de abastecimento estavam associados à questão da oferta de alimentos para a população. Desse período até o final dos anos 80 , a fome passou a ser encarada como um problema de intermediação e as políticas se voltaram para a regulação de preços e controle da oferta. A partir dos anos 90 , os problemas de abastecimento passaram a ser combatidos, supostamente, através da desregulamentação do mercado na esperança de que o crescimento econômico pudesse proporcionar renda, emancipando as famílias pobres e alcançando a cidadania.

Palavras-chave: pobreza e fome; política de abastecimento; política agrícola.
\end{abstract}

$\mathrm{A}$ dificuldade de medir, de forma direta, a quantidade de pessoas que passam fome é um problema generalizado em todos os países, pois exige pesquisas extensas e dispendiosas (FAO, 1996). A pesquisa que mais se aproximou desse objetivo, no Brasil, foi o Endef (Estudo Nacional da Despesa Familiar), de 1974-75, que mensurou o consumo de alimentos e a renda das famílias. Ante a ausência de pesquisas diretas, inúmeros pesquisadores - entre os quais destacam-se técnicos do Ipea, da Cepal, do IBGE e de várias universidades - desenvolveram metodologias diversas para seu dimensionamento. Em geral são metodologias baseadas na mensuração indireta da "fome" a partir da insuficiência de renda monetária para alimentar-se adequadamente, que iremos chamar aqui de "vulnerabilidade à fome". Takagi, Graziano da Silva e Del Grossi (2001) levantaram os estudos mais recentes para a mensuração da indigência e da pobreza no Brasil. ${ }^{1}$ Eles verificaram disparidade muito grande nos resultados, variando de $8,7 \%$ de indigentes (Rocha, 2000) a 29,0\% (Camargo e Ferreira, 2001), a partir dos dados da PNAD de 1999. Recente trabalho da FGV-RJ, lançado em julho de 2001, denominado Mapa do Fim da Fome (ver www.fgv.br), utilizando metodologia similar à adotada em Ferreira, Lanjouw e Néri (2000), chegou ao valor de 49,8 milhões de indigentes ou $29,3 \%$ da população, em 1999 , considerando uma linha de indigência de $\mathrm{R} \$ 80,00$, referente à Região Metropolitana de São Paulo. O trabalho também quantificou a pobreza nos municípios brasileiros com mais de 100 mil habitantes. O Instituto Cidadania, por sua vez, estimou em 9,3 milhões de famílias e 44 milhões de pessoas muito pobres, com renda familiar per capita abaixo de um dólar diário, em 1999.

Os estudos são unânimes no diagnóstico de que o problema da fome no País, atualmente, é a falta de renda para alimentar-se adequadamente, e de que essa falta de renda, traduzida por pobreza, é o reflexo da desigualdade de renda existente no País (Henriques, 2000), agravada pelos altos níveis de desemprego, e das taxas de crescimento econômico insuficientes para incorporar as pessoas que a cada ano querem ingressar no mercado de trabalho, além da falta de políticas públicas no campo da segurança alimentar.

O diagnóstico e as políticas receitadas para o combate à fome no Brasil passaram por três fases. Até os anos 30, os problemas de abastecimento estavam associados à questão da oferta de alimentos para a população que crescentemente se dirigia às metrópoles. Desse período até o final dos anos 80 , a fome passou a ser encarada como um problema de intermediação e as políticas se voltaram para a regulação de preços e controle da oferta. Finalmente, com o início dos anos 90 , os problemas de abastecimento passaram a ser combatidos, supostamente, através da desregulamentação do mercado na esperança de que o crescimento econômico pudesse proporcionar renda, emancipando as famílias pobres e alcançando a cidadania. 
Embora tenha havido mudança no diagnóstico e nas políticas prescritas, o problema da vulnerabilidade à fome permanece no início deste século tão ou mais grave quanto antes. As últimas estatísticas têm mostrado não a diminuição contínua dos níveis da pobreza e da indigência, mas a manutenção dos níveis a partir de 1995 e até mesmo seu ligeiro aumento em 1999 (Rocha, 2000; Hoffmann, 2001 e Takagi, Graziano da Silva e Del Grossi, 2001), especialmente nas áreas metropolitanas, ${ }^{2}$ como reflexo do crescente desemprego, da precariedade dos mercados de trabalho e dos baixos salários vigentes.

\section{INTERVENÇÕES NA ÁREA DO ABASTECIMENTO}

Apesar de o Brasil colonial estabelecer-se como área de exploração e produção agrícolas, a preocupação com as culturas alimentares surge já no século XVI em função da monocultura, que não deixava espaço para a produção de "mantimentos". Ao longo do período de escravidão, desenvolveu-se o dilema entre utilizar essa mão-de-obra para produzir e comercializar alimentos em condições não remuneradoras e a alternativa de produzir para a exportação. Por esse motivo, a produção de alimentos esteve ligada muito mais ao auto-abastecimento das propriedades que às demandas colocadas pelo mercado. Essa situação abria espaço para alguns colonos na região de Minas Gerais ou foreiros e escravos que trabalhavam nas fazendas de cana-de-açúcar paulistas.

Segundo Burnier (2000:45), outros dois flagelos da administração colonial eram o dízimo e o recrutamento. "O recrutamento era feito de forma aleatória e desordenada, tendo chegado na Bahia a provocar a carestia de alimentos: para fugir dele, muitos lavradores optavam por abandonar suas plantações". Com a introdução do café e a cessação do tráfico negreiro, o problema da oferta de alimentos se agravou. Faltavam braços para cultivar a terra e havia mais bocas para alimentar nas cidades. A situação era ainda pior em períodos de alta no preço do café, quando a mão-de-obra disponível era totalmente aproveitada para o desenvolvimento dessa cultura de exportação.

A escassez de alimentos e o atraso nas estruturas de comercialização levaram à elevação no preço dos alimentos e à ação de especuladores. O ano de 1917 representa um marco nos problemas de alimentação, com o problema da carestia apresentando-se como o estopim para a deflagração de manifestações e da primeira greve geral operária de nossa história, que teve lugar na cidade de São
Paulo. Na realidade, a escassez estava sendo gerada pelos crescentes embarques de alimentos brasileiros para o abastecimento das nações européias em guerra (Fritsch, 1990:45). O mercado não queria café, cujos preços estavam em baixa, e sim alimentos. Isso levava a um enorme esforço das fazendas em situação financeira debilitada para desviar o produto agrícola que atendia a uma população urbana já na casa de milhões.

A crise dos anos 30 inaugura um período de intervenções públicas federais no abastecimento. O governo Vargas implantou um largo aparato de intervenção no qual cada autarquia (açúcar e álcool, mate, sal, café, trigo, etc.) deveria zelar pelo equilíbrio dos mercados interno e externo e pelos preços remuneradores aos produtores. É justamente nesse período que se agrava o problema da oferta, tendo em vista a desestruturação da agricultura cafeeira. Esta, por um lado, contribuía para a oferta de gêneros de primeira necessidade e, por outro, segurava um grande contingente populacional no campo.

A Comissão de Abastecimento, criada no período da ditadura, compatível com o esforço de guerra (DecretoLei ${ }^{\circ} 1.507$ de 16 de setembro de 1939), tinha como objetivo regular tanto a produção como o comércio de alimentos, drogas, material de construção e combustíveis, a fim de segurar a alta de preços. A Comissão funcionava como um ministério extraordinário com superpoderes, podendo comprar ou requisitar e vender esses produtos para a população. Ela poderia também exigir a colaboração de órgãos ou funcionários estaduais e municipais.

Em termos práticos, a Comissão deixou algumas iniciativas importantes como os restaurantes populares - vinculados ao Ministério do Trabalho e ao órgão de Previdência Social - e também alguns instrumentos de incentivo e apoio à produção agrícola. Os preços da alimentação, todavia, continuam a elevar-se durante o período da guerra e mesmo nos anos seguintes. A causa principal para esse movimento estava na desvalorização da moeda nacional que tornava mais caras as importações e escassos os produtos de origem nacional.

Nas décadas seguintes, a questão da fome e da carestia começa a receber uma atenção especial dos governantes por causa dos aspectos concernentes às questões de produção, consumo e distribuição ou em virtude de questões subjetivas ligadas a um país que queria libertar-se do atraso e do subdesenvolvimento e entrar na modernidade. Como pano-de-fundo desses temas estavam os compromissos assumidos internacionalmente pelo Brasil em 1943, na Conferência de Hot Springs (EUA), que lançou as bases 
para a criação da FAO - Food and Agriculture Organization, das Nações Unidas, e na própria criação da FAO em 1945. Nesse período, o brasileiro Josué de Castro tornava-se conhecido mundialmente com a publicação do seu livro Geografia da fome, em 1946.

Nos anos 50, com a modernização da agricultura e a abertura de novas vias de acesso e novas áreas de produção, o discurso político e a ação governamental voltamse para a área da distribuição. Embora a Reforma Agrária passasse a ser apresentada como importante política de apoio à oferta de alimentos, e viesse no sentido mais geral das reformas necessárias para o desenvolvimento do país, a ênfase da política do período vai se dar na área do abastecimento. Pela primeira vez, são tomadas medidas de intervenção direta no abastecimento em tempos de paz.

Nesse sentido, vale mencionar a criação da Cofap Comissão Federal de Abastecimento e Preços em 1951, que mais tarde abriu espaço para uma área de fiscalização (Sunab), armazenamento (Cibrazém), distribuição (Cobal) e administração de estoques reguladores (CFP). Todos esses órgãos foram lançados dez anos depois, através das leis delegadas, numa tentativa do governo Goulart de recuperar o atraso existente entre as estruturas de produção e comercialização e deter a especulação. Nesse período também é criado o Entreposto Terminal de São Paulo, que foi o embrião do Ceagesp e das Centrais de Abastecimento que se seguiram.

O surgimento do entreposto em São Paulo e a criação da Cobal marcam uma mudança radical no rumo das políticas de abastecimento. Até então, o poder público tinha como objetivo apenas fiscalizar e controlar os canais de comercialização. A partir da década de 60 , o poder público chama para si a tarefa de distribuir e fazer chegar até o consumidor os alimentos necessários. Em outras palavras: deixam-se de lado os aspectos normativos e a atuação passa a ser direta na gestão do sistema de abastecimento. A preocupação principal não era combater diretamente o problema da fome, mas sim dar uma resposta à sociedade que exigia preços mais baixos.

A partir da proposta inicial do Gemab - Grupo Executivo de Modernização do Abastecimento, em 1968, e da Cobal, institui-se extensa rede de centrais de abastecimento (47 entrepostos) e mais de uma centena de instalações varejistas (Rede Somar). Adicionem-se a isso outras centenas de varejões e sacolões administrados pelos Estados e municípios que irão surgir ao longo dos anos 70 e 80 . Essa postura é bastante distinta da anterior, que mantinha sob a administração pública apenas o esquema de conces- sões em mercados municipais. Desta feita, o Estado pretende administrar, direcionar e punir os varejistas. Acreditava-se que reunindo em um só local oferta e demanda de produtos agrícolas seria possível nivelar preços, comparar padrões e reduzir margens.

\section{MUDANÇAS NA CONJUNTURA NOS ANOS 70 E 80: PRIORIDADE PARA A PRODUÇÃO AGROPECUÁRIA}

O esforço de modernização da agricultura brasileira afastou a preocupação com a disponibilidade de alimentos. Desde a década de 50, a produção agrícola passou a crescer em ritmo superior ao aumento da população. No final dos anos 60, a agricultura e a pecuária cresceram aceleradamente $(5,1 \%$ e $2,3 \%$ ao ano, respectivamente, para o período 1967-1970) e, no período seguinte, 1971-1976/ 1977, atingem seus maiores níveis de crescimento na história: $5,5 \%$ e $6,3 \%$ para agricultura e pecuária.

O principal fator impulsionador da agricultura no período foi a política de crédito rural subsidiado. O resultado foi rápida expansão da fronteira agrícola, o que demandou, evidentemente, uma rede de estradas e corredores que permitisse escoar a produção agrícola para o mercado. Assim, embora a produção agrícola fosse suficiente para atender às necessidades nutricionais - mesmo considerando a crescente exportação de produtos agrícolas - e parte importante da distribuição estivesse sob controle do poder público, os preços dos alimentos continuavam elevados e a questão da fome já se destacava na realidade brasileira associada à questão da carestia dos alimentos e à inflação. Entre 1971 e 1980, o IPA - Índice de Preços no Atacado de produtos agrícolas (IPA-DI) apresentou taxa média anual de $30,4 \%$ contra um IPA-DI para todos os produtos da ordem de $27,6 \%$. Na década seguinte, no período 1981-1990, esse índice subiu para 208,5\% (média anual) contra $203,9 \%$ do IPA-DI (média anual) para todos os produtos. ${ }^{3}$

Muitos fatores poderiam ser arrolados para explicar essas diferenças de indicadores, como a influência do câmbio valorizado nos custos dos insumos agrícolas, menores ganhos de produtividade no campo, desvios de produção para o mercado externo, etc. No entanto, dois aspectos podem ser considerados fundamentais para compreender a reversão de políticas que se processa nos anos 90 .

Primeiro, a ineficiência das estruturas de comercialização. Apesar de todo o aparato montado ao longo dos 30 anos anteriores, o poder público foi ineficiente em con- 
trolar preços e margens e em modernizar a comercialização. No sistema de atacado, as Ceasas jamais funcionaram como espaços de aproximação de produtores e consumidores. Ao contrário: tão logo elas se estabeleceram, o sistema passou a ser controlado por atacadistas privados que se consolidaram como um novo elo na cadeia de distribuição. Durante todo esse período, pouca coisa se alterou também no sistema de escoamento da produção, embalagens e mecanismos de formação de preços. Na prática, os agentes e os mercados tradicionais passaram a atuar nos novos espaços patrocinados pelo poder público sem mudanças e maiores efeitos na oferta.

Segundo, a importância cada vez maior do peso dos produtos industrializados na cesta de consumo da população. Essa particularidade chamou a atenção de Baer (1995:370), em sua análise da estrutura de consumo pessoal do Brasil, calculada a partir das Contas Nacionais. Observa-se que a proporção do consumo de produtos agrícolas in natura nos gastos totais com consumo reduziu-se de $17,4 \%$ para $5,4 \%$ e depois para $3,3 \%$ entre 1959,1970 e 1975. Por sua vez, o consumo de alimentos industrializados cresceu de $15,1 \%$ para $25,3 \%$ e depois se reduziu para $21,12 \%$ no período analisado.

De fato, com a urbanização e a mudança dos hábitos alimentares da população, cresceu o consumo de produtos industrializados ou semipreparados. Assim, uma parte cada vez mais importante da produção agrícola acabava por seguir outros circuitos, passando de um bem final de consumo a um insumo para a indústria de alimentos e, daí, para os supermercados e mercearias. ${ }^{4}$

Acrescente-se a isso também as mudanças ocorridas na estrutura familiar e no mercado de trabalho, que levaram a um crescente consumo de alimentos fora dos domicílios. Dados observados por Maluf (2000:9) chamam a atenção para o fato de, mesmo nas classes de renda mais baixa (até $2 \mathrm{SM}$ ), o gasto com alimentação fora de casa saltar de quase nada no total gasto com alimentação para mais de $12 \%$ em 1999. Esses fatores têm enorme influência não só nos circuitos de distribuição dos alimentos industrializados mas também dos in natura. Estamos considerando, portanto, que uma importante parcela da produção não recebe qualquer influência ou regulação do poder público e circula de forma independente, passando a criar as próprias rotinas de compras.

Esses elementos nos permitem mostrar que a ação do Estado na regulação da distribuição e no combate aos problemas da fome mudou nos seus fundamentos. Nos anos 90 , assistimos ao desmonte das estruturas antigas e o res- surgimento de políticas de assistência direta à população carente.

Em comparação com o enorme apoio recebido pela produção agrícola, foram poucas as ações do Estado em direção a uma política de abastecimento e combate à fome. Nos anos 70, consolidou-se o sistema de Centrais de Abastecimento concebido nos anos 80 e a distribuição varejista ficou sob responsabilidade dos Estados e municípios, que incrementaram e ampliaram a rede de varejões e sacolões. A única iniciativa federal efetiva, visando atender consumidores de baixa renda, foi a criação da Rede Somar que, conforme já comentado, chegou a administrar mais de uma centena de estabelecimentos.

Merece ser lembrado apenas, nesse período, o Programa Nacional do Leite para Crianças Carentes (PNLCC), criado em 1986 no governo Sarney, para atender família com renda mensal total até 2 Salários Mínimos e crianças de até 7 anos de idade. Como destaca Cohn (1995), o programa foi muito malsucedido em sua abrangência e gestão. Entretanto, foi a primeira experiência em grande escala de distribuição de cupons de alimentos no Brasil.

O PNLCC estava vinculado diretamente à Presidência da República, e controlava a oferta (produção e importação de leite) e o sistema de distribuição. Os cupons, conhecidos como "tíquetes do Sarney" eram distribuídos às famílias carentes previamente cadastradas em entidades de base, na proporção de um litro de leite por criança. Não havia contrapartida por parte dessas famílias, nem controles que pudessem conferir se os cupons estavam mesmo sendo trocados por leite.

Embora não haja informações sobre o custo desse programa e sobre os resultados das metas estabelecidas - atender mais de 10 milhões de crianças (Secretaria de Agricultura e Abastecimento, 1986:17) - observou-se aumento significativo na produção de leite no país $(20,1 \%$ entre 1986 e 1990) e crescimento no consumo per capita de 94 litros/ano para 109 litros/ano nesse período. Vale lembrar, também, que essa foi a primeira experiência na implementação de políticas, cujas metas foram traçadas de baixo para cima. Foi também a primeira experiência de compra pública de gêneros alimentícios feita diretamente na rede comercial constituída. Não se estabeleceram novos canais de comercialização nem se distribuiu alimento em espécie, e sim o meio de compra para a aquisição de alimentos.

As mudanças nas diretrizes da política macroeconômica nos anos 90 levaram à redução gradativa dos gastos 
com agricultura e alimentação. Tomando-se apenas as despesas orçamentárias do governo federal, verifica-se que os recursos alocados na "função agricultura", reduzem-se de 5,75\% no início dos anos 80 , para apenas $2,11 \%$ na média do período 1995-1999 (Gasques, 2001). Embora tenha havido crescimento dos gastos ao longo desse período, esse foi muito inferior ao crescimento dos gastos do governo. Enquanto a taxa anual de crescimento dos gastos com a agricultura cresceu $4,22 \%$, as despesas gerais tiveram um crescimento médio de $12,21 \%$ ao ano. Vale ressaltar ainda que "mais de $50 \%$ do gasto público estão pulverizados em ações sobre as quais o governo não tem o menor acompanhamento ou controle" (Gasques, 2001:11 e 29).

Com o esvaziamento das despesas de governo com a agricultura (leia-se: crédito agrícola, preços mínimos e estoques reguladores), restou ao Estado promover políticas compensatórias. Nesse particular, inserem-se políticas pontuais e regionais visando atender às demandas de grupos organizados. Não seria exagero afirmar que, com a importante exceção dos recursos destinados à Previdência Rural (estabelecidos pela Constituição de 1998), houve uma redução generalizada dos gastos em programas e ações na área social. Na agricultura, assim como em outros setores, houve um redirecionamento das fontes públicas para as de origem privada.

A mudança de enfoque não abalou tanto o crescimento da agricultura empresarial, especialmente dos segmentos voltados à exportação, que continuaram a apresentar resultados crescentes em termos de quantidades produzidas. Parcela cada vez maior de pequenos agricultores, todavia, passou a conviver com a situação de insolvência, deixando de lado a atividade agrícola. Dias et alii (2000) estimam, com dados do IBGE de 1996, que aproximadamente $20,4 \%$ dos produtores agrícolas tinham rendas negativas e $59,5 \%$ abaixo da renda mediana, o que quer dizer que se tratava de agricultores eminentemente pobres.

\section{A RETOMADA DA QUESTÃO DA FOME NOS ANOS 90}

Embora nunca tenha saído da pauta de problemas nacionais, nem de reivindicações dos movimentos sociais, houve um arrefecimento da discussão sobre o problema da fome e da miséria no País desde a mobilização promovida pela Ação da Cidadania contra a Fome, a Miséria e pela Vida e da extinção do Consea (Conselho Nacional de Segurança Alimentar), em 1993.
Sua retomada, no início dos anos 2000, está relacionada com vários fatores: primeiro, o agravamento da situação de pobreza e da vulnerabilidade das famílias no País, especialmente nas grandes cidades, aprofundada pela crise econômica e pelo aumento do desemprego no final da década de 90. Segundo, as iniciativas dos organismos internacionais, como a FAO, a ONU e o Banco Mundial, sobre o tema da fome e da pobreza. ${ }^{5}$ Essas preocupações e ações refletem o fato de que a manutenção da pobreza e de níveis agudos de fome (e até mesmo seu aumento em alguns países) é o calcanhar-de-aquiles para o "sucesso" do "modelo de desenvolvimento equilibrado" dessas economias.

A Cúpula Mundial da Alimentação em Roma, 1996, que reuniu 186 países, definiu como meta reduzir pela metade o número de desnutridos até o ano 2015, o que fez com que a FAO adotasse uma metodologia para acompanhamento da quantificação da fome no mundo. Similarmente, o Banco Mundial acompanha os dados de pobreza no mundo desde 1993, sendo que seu último relatório sobre desenvolvimento mundial (2000/2001) denomina-se "Luta contra a Pobreza". O Programa das Nações Unidas para o Desenvolvimento - PNUD, na mesma linha, adotou o compromisso de reduzir pela metade a extrema pobreza no mundo, e também publica anualmente avaliações sobre o estado de desenvolvimento humano mundial, acompanhando indicadores sociais.

Ao contrário de outros países (desenvolvidos ou não) que têm adotado políticas claras para aumentar o acesso da população à alimentação, o Brasil ainda se ressente da falta de um projeto integrado e com recursos para atender a esse objetivo. A seguir, apresenta-se um rápido resumo sobre as marchas e contramarchas das políticas de combate à fome no Brasil nos anos 90 .

No início da década de 90, o governo Collor de Melo reestruturou os órgãos e instrumentos de políticas ligados à saúde e nutrição, extinguindo políticas como os programas de suplementação alimentar dirigidos a crianças menores de 7 anos, e enfraquecendo outras, como o Programa Nacional de Alimentação Escolar, o Programa de Alimentação do Trabalhador e o Inan (Instituto Nacional de Alimentação e Nutrição) (Valente, 2001). Segundo Valente, a única novidade positiva no período foi a iniciativa de utilização de estoques públicos de alimentos para Programas de Alimentação, uma reivindicação antiga de técnicos para reduzir as perdas dos estoques, originando o programa de distribuição de cestas básicas para a população atingida pela seca do Nordeste, em 1990. 
O período seguinte (1992/1994) é marcado pela realização de ampla mobilização da sociedade civil em torno do tema da fome e da miséria, impulsionada pela mobilização pela ética na política, resultando na tentativa de implantação, pela primeira vez, de uma política de combate à fome no País. As iniciativas de partidos políticos da oposição, como o Partido dos Trabalhadores, ao elaborar uma Política Nacional de Segurança Alimentar e apresentá-la ao governo federal, e a mobilização da sociedade em torno da campanha da Ação da Cidadania contra a Fome, a Miséria e pela Vida, coordenada pelo sociólogo Betinho, tiveram forte impacto. Como resultado dessa mobilização, foi criado, em maio de 1993, na gestão Itamar Franco, o Consea, vinculado diretamente à Presidência da República e com a participação de organizações não-governamentais. Segundo Valente (2001), o Consea era integrado por 8 ministros e 21 representantes da sociedade civil, em grande parte indicados pelo Movimento pela Ética na Política, para coordenar a elaboração e implantação do Plano Nacional de Combate à Fome e à Miséria dentro dos princípios da solidariedade, parceria e descentralização.

O Consea chegou a funcionar por apenas dois anos. Apesar de representar uma novidade institucional, ao envolver vários ministérios e também segmentos organizados da sociedade civil, ficou sujeito às restrições da área econômica, cuja prioridade de estabilização monetária deixava à margem as políticas sociais. Alguns dos poucos resultados que podem ser atribuídos à atuação do Consea foram a descentralização do Programa Nacional de Alimentação Escolar (a merenda escolar) em direção aos municípios e às próprias escolas (autonomização da gestão); a continuidade do Prodea, com a utilização de estoques públicos de alimentos; e a prioridade ao programa de distribuição de leite (Programa "Atendimento ao Desnutrido e à Gestante em Risco Nutricional Leite é Saúde"), como estratégia de combate à desnutrição materna e infantil.

O governo Fernando Henrique Cardoso extinguiu o Consea e, no lugar dele, criou o Conselho Comunidade Solidária, um órgão mais de consulta que executivo. A partir daí, observa-se uma nova fragmentação das políticas públicas de combate à fome, que resultou, por exemplo, na extinção do Inan, em 1997, e na manutenção do programa de distribuição de cestas básicas de forma instável e sujeito ao calendário eleitoral. Em 1998, ano eleitoral, o governo distribuiu o recorde de 30 milhões de cestas básicas (conforme editorial do jornal Folha de S.Paulo em 28/11/00).

Em 1999, foi criado o Programa Comunidade Ativa (PCA), coordenado pela Secretaria Executiva do Co- munidade Solidária. O PCA é voltado para as localidades, sendo os municípios escolhidos por terem menor IDH (Índice de Desenvolvimento Humano). A proposta do programa é a realização de agendas de desenvolvimento a partir de diagnósticos participativos para identificação dos problemas locais. A partir dessas agendas, o governo federal dá prioridade a essas localidades em programas como Redução da Mortalidade Infantil, Agentes Comunitários de Saúde, Saúde da Família e programas de microcrédito (Terra, 2000). Segundo Valente (2001), no início de 2001, apenas 157 municípios haviam sido contemplados na primeira fase do programa, contra a previsão inicial de atingir 1.000 até o final de 2000. A mesma proposta do PCA foi, posteriormente, incorporada em novo programa do governo federal, o Projeto Alvorada, que é uma junção de diversos outros programas em andamento e implantados em cada ministério.

Com relação às políticas na área de saúde, desde a extinção do Inan, o principal programa federal para combate às carências nutricionais à população de risco tem sido o fornecimento de leite e óleo de soja. Isso vem sendo feito através do programa de Incentivo ao Combate às Carências Nutricionais - ICCN, vinculado à Política Nacional de Alimentação e Nutrição - PNAN, do Ministério da Saúde, juntamente com o fornecimento da multimistura para crianças desnutridas, através da Pastoral da Criança. $\mathrm{O}$ governo federal planeja substituir progressivamente o ICCN por um programa de renda mínima, o Bolsa-Saúde, a partir de 2001. A proposta é de uma complementação monetária de $\mathrm{R} \$ 20,00$ por nutriz, gestante ou criança até seis anos, com no máximo três beneficiários por família, com um valor total previsto de cerca de R $\$ 570$ milhões.

No final de 2000, o governo federal cortou, do Orçamento de 2001, a verba para o Prodea, acabando com a distribuição de cestas básicas. A justificativa oficial foi o caráter assistencial do programa, que não contribui, segundo o governo, para o combate à pobreza no país. Além disso, argumentou-se que a distribuição de cestas vindas de fora não ajuda a economia local do município, porque diminui as compras nos pequenos comércios. A proposta do governo federal, desativando o Prodea, era transferir gradativamente as famílias atualmente beneficiadas para outros programas sociais vinculados ou não ao Projeto Alvorada, com especial ênfase no Bolsa-Alimentação, recém-criado, e no Bolsa-Escola, a partir de 2001.

O Bolsa-Escola federal, criado em fevereiro de 2001 e implantado pelo Ministério de Educação, visa fornecer a 
quantia de $\mathrm{R} \$ 15,00$ por mês para cada criança matriculada na escola, com no máximo $\mathrm{R} \$ 45,00$ por família, através de recursos previstos de $\mathrm{R} \$ 1,7$ bilhão, provenientes do Fundo de Combate à Pobreza. ${ }^{6}$ A meta do governo é atingir 10,7 milhões de crianças e 5,9 milhões de famílias em 2001. O valor da bolsa é menor que o valor de mercado da cesta básica distribuída pelo Prodea - esta, segundo cálculos de Lavinas et alii (2000), variava de $\mathrm{R} \$ 18,90$ em Curitiba a R\$21,66 em Belo Horizonte - e bem menor do que o das políticas que deram origem ao Programa Bolsa-Escola, como na Prefeitura de Campinas (gestão Magalhães Teixeira, 1997/2000, cujo valor, hoje, varia de R $\$ 125,00$ a R \$370,00 por família), no Distrito Federal (gestão de Cristovam Buarque, 1995/1998 de R \$ 130,00 por família - o salário mínimo da época), e nas Prefeituras de Porto Alegre, de R $\$ 150,00$ por família, e de Recife, no valor de $\mathrm{R} \$ 75,00$ por aluno matriculado (Azevedo et alii, 2001).

Em resumo, é possível identificar duas tendências atuais nas políticas de combate à fome do governo federal: primeira, um esvaziamento das políticas universais e sua substituição por políticas compensatórias localizadas, de caráter focalizado e geridas pelos próprios municípios, voltadas para a área social em geral (Lobato, 2001). Dá-se prioridade aos municípios mais pobres e procura-se implantar, gradualmente, agendas locais, apostando na mobilização, formação e treinamento de agentes locais de desenvolvimento. $\mathrm{O}$ alcance dessa política tem se revelado bastante limitado, como se pode verificar pelos baixos resultados alcançados até o momento na redução dos desequilíbrios sociais. Isso porque a fome no Brasil tem, cada vez mais, determinantes globais - como a crise econômica, que resulta em desemprego e baixos salários, além da extrema desigualdade social no País - e menos determinantes locais. ${ }^{7}$

A segunda tendência é a substituição de programas baseados na distribuição de bens em espécie (como cestas básicas e leite) por um valor mensal em dinheiro, variando entre R $\$ 15,00$ e R $\$ 20,00$ por mês. O agravante é que essas novas políticas direcionadas para a população mais vulnerável à fome não prevêem formas de emancipação do dependente do benefício nem de acompanhamento, para verificar se as famílias realmente solucionam a carência alimentar. $^{8}$

\section{PROPOSTAS PARA O COMBATE À FOME}

Na nossa opinião, o problema da fome no Brasil neste início do século XXI está relacionado com uma insuficiên- cia de demanda efetiva, que inibe a maior produção de alimentos por parte da agricultura comercial e da agroindústria do País. As razões que determinam essa insuficiência da demanda efetiva - concentração excessiva da renda, baixos salários, elevados níveis de desemprego e baixos índices de crescimento, especialmente daqueles setores que poderiam expandir o emprego - não são conjunturais. Ao contrário, são estruturais, ou seja, endógenas ao atual padrão de crescimento e, portanto, resultados inseparáveis do modelo econômico vigente. Forma-se, assim, verdadeiro ciclo vicioso e acumulativo, causador em última instância do aumento da fome no País, qual seja, desemprego, queda do poder aquisitivo, redução da oferta de alimentos, mais desemprego, maior queda do poder aquisitivo, maior redução na oferta de alimentos.

Para romper esse ciclo perverso, é preciso a intervenção do Estado com um autêntico programa keynesiano, de modo a incorporar ao mercado de consumo de alimentos aqueles que estão excluídos do mercado de trabalho e/ou que têm renda insuficiente para garantir uma alimentação digna a suas famílias.

Trata-se, em suma, de criar mecanismos - alguns emergenciais, outros permanentes - no sentido de: baratear o acesso à alimentação para a população de mais baixa renda, em situação de vulnerabilidade à fome; incentivar o crescimento da oferta de alimentos baratos, mesmo que seja através do autoconsumo e/ou da produção de subsistência; e, finalmente, incluir as famílias através do aumento da renda, da universalização dos direitos sociais e do fornecimento de direitos de compra de alimentos, dado que o acesso à alimentação básica é direito inalienável de qualquer ser humano, para não falar do direito de cidadão, que deveria ser garantido a todos os brasileiros.

Para o equacionamento definitivo do problema da fome, é necessário, conforme foi dito, um novo modelo econômico que privilegie o crescimento do mercado interno e que diminua a extrema desigualdade de renda existente no País. Enquanto isso é buscado, pode-se implementar uma série de políticas que promovam melhorias na renda das famílias, barateamento da alimentação, aumento da oferta de alimentos básicos e, simultaneamente, forneçam de forma emergencial alimentos à população vulnerável à fome.

A Figura 2 apresenta, esquematicamente, os principais eixos de atuação e as principais políticas para combater a fome no País. As propostas apresentadas tratam, basicamente, de uma compilação de iniciativas já implementa- 


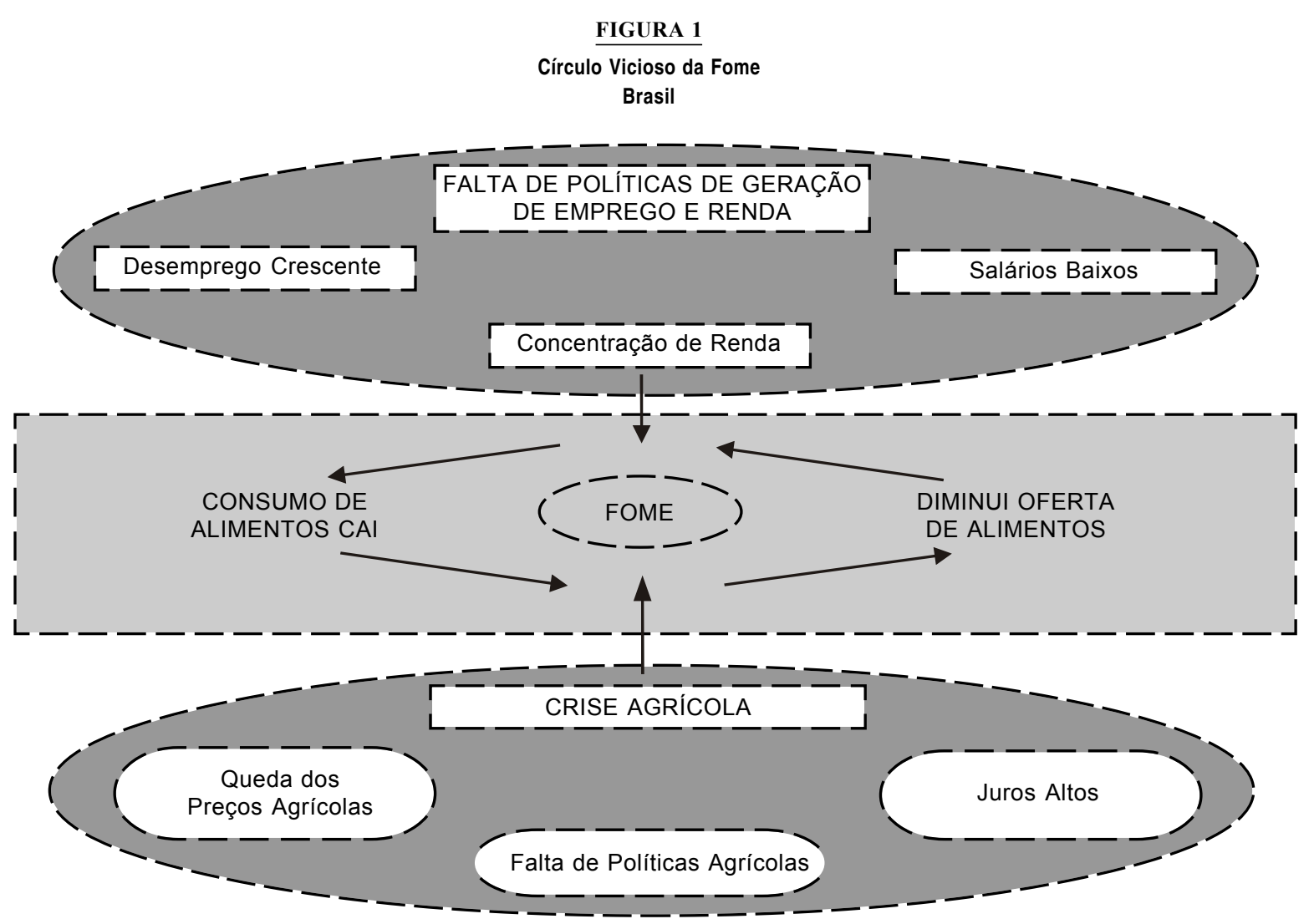

Fonte: Instituto Cidadania.

das ou em implementação no Brasil ou em outros países que, se implementadas de forma conjunta, podem reduzir efetivamente a fome. O fundamental, a nosso ver, não é propor "novas" políticas, mas integrá-las, articulando os diversos níveis de governo (federal, estadual e municipal) com os segmentos da sociedade civil para garantir sua implementação.

Esquema de uma Política Integrada de Combate à Fome: Melhoria da Renda - As iniciativas de fornecimento de renda para as famílias carentes (através de programas de renda mínima, bolsa-escola e previdência social universal) são importantes para a melhoria da renda familiar, mas sozinhas não conseguem solucionar o problema alimentar de segmentos importantes da população carente. Associam-se, também, a este grupo, programas de geração de emprego e renda, a reforma agrária, com o papel fundamental de fornecer "casa, comida e trabalho" às famílias rurais mais pobres, e políticas de estímulo à produção de alimentos para o autoconsumo, como fornecimento de mudas, sementes, insumos, matrizes de pequenos animais, etc.
Barateamento da Alimentação - As iniciativas dos restaurantes populares, que fornecem refeições prontas a preço baixo $(\mathrm{R} \$ 1,00$ a $\mathrm{R} \$ 2,00)$ à população trabalhadora que mora nas periferias das grandes cidades, têm tido sucesso no barateamento da alimentação que é realizada fora de casa. Outra iniciativa importante é a dos canais alternativos de comercialização, como varejões, feiras livres, sacolões, feira do produtor, compras comunitárias que fornecem alimentos de qualidade e de baixo custo, pela redução da intermediação. A formação de centrais de compras nas periferias em parcerias com o poder público, agregando pequenos supermercados para racionalizar a logística e diminuir seus custos, visando à redução dos preços finais, é alternativa a ser incentivada. Parcerias com as redes de varejo de vizinhança são possíveis em programas como os cupons-alimentação, como será apresentado nas ações emergenciais. Por fim, é preciso ampliar o Programa de Alimentação do Trabalhador - PAT, de modo a atender também os empregados das micro e pequenas empresas. 
FIGURA 2

Esquema de uma Política Integrada de Combate à Fome

Brasil

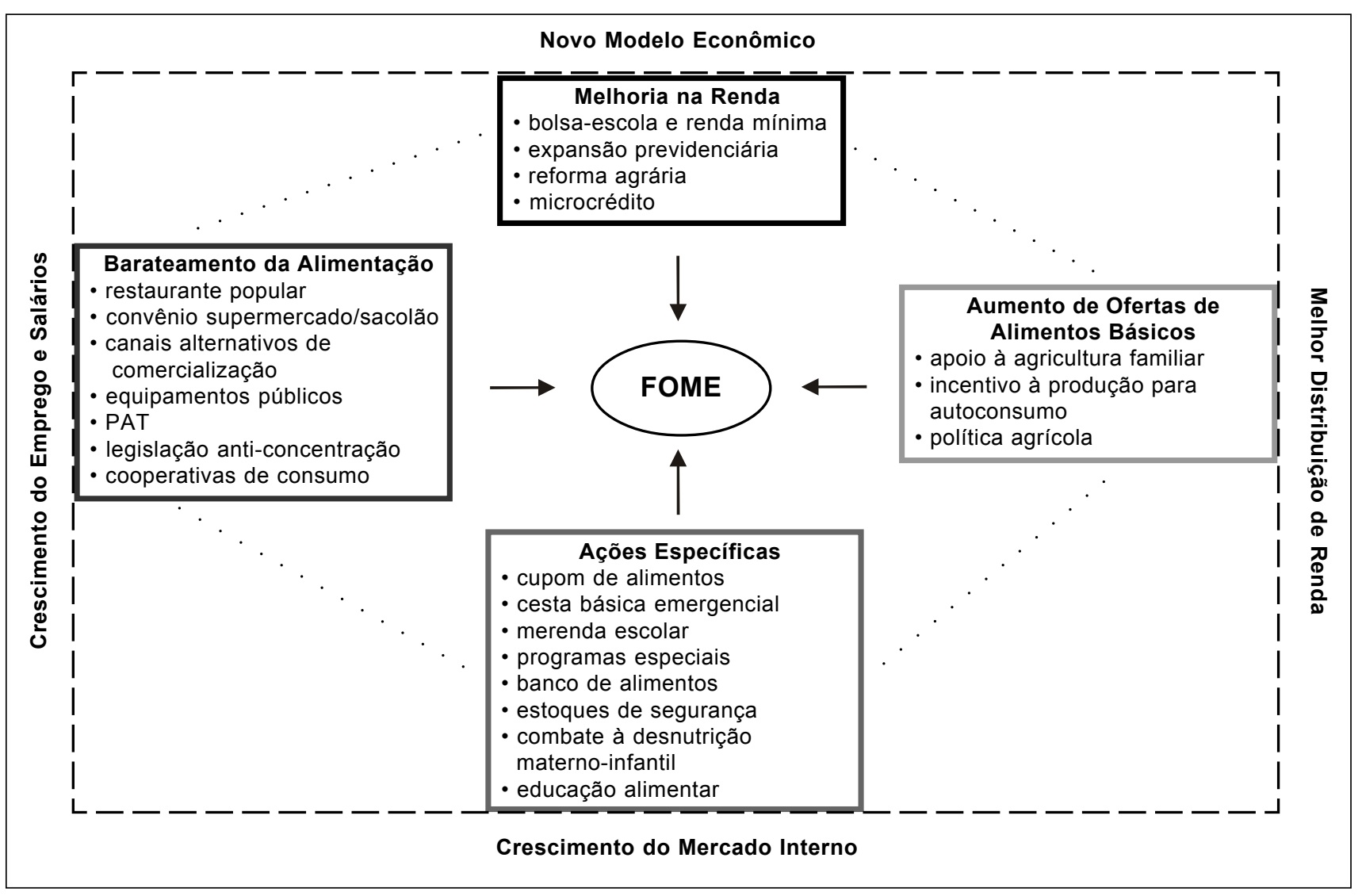

Fonte: Instituto Cidadania.

Ações Específicas - Paralelamente às ações já apontadas, é necessário atender, de forma emergencial, as famílias que já sofrem o efeito da fome e/ou que sejam vulneráveis a ela, por não ter renda para se alimentar adequadamente. Esses programas específicos devem atender todas as famílias com renda insuficiente para alcançar a segurança alimentar. A exemplo do programa americano Food Stamp, que fornece às famílias pobres selos (ou vales) para compra de alimentos no comércio local, propõese que sejam fornecidos cupons de alimentação para as famílias completarem sua renda até o valor correspondente ao da Linha de Pobreza de cada região do País. Esses cupons poderão ser trocados por alimentos em estabelecimentos cadastrados, e podem ser geridos conjuntamente pelo governo federal e por governos estaduais e municipais. Além de fornecer meios para as famílias se alimen- tarem, o programa visa incentivar o comércio local (através de parcerias com os estabelecimentos cadastrados) e o consumo de produtos naturais (através de centrais de compras em parceria com associações de produtores agrícolas), permitindo, ao mesmo tempo, que cada família construa o próprio cardápio. O programa de cestas básicas deve ser mantido, mas assumindo caráter exclusivamente emergencial, para aqueles segmentos da população atingidos por calamidades naturais (secas e enchentes) e para os novos assentados de reforma agrária, até que se desenvolva o comércio local e as famílias possam ser atendidas pelo programa do cupom-alimentação. O fornecimento das cestas básicas emergenciais poderá ser garantido pela instituição de estoques públicos de segurança alimentar, conforme defendido por organismos internacionais como a FAO, desvinculados dos estoques agrícolas 
destinados a evitar oscilações de preços. Além desses, devem-se manter programas nas áreas de saúde, com o acompanhamento da situação nutricional de crianças e adultos e o fortalecimento da ação do Sisvan (Sistemas de Vigilância Nutricional) nos municípios, de forma a monitorar a situação de carência alimentar das famílias de baixa renda.

Combate ao Desperdício - Especialmente nas grandes cidades, verifica-se a existência de uma rede de produção e desperdício de alimentos prontos ou não que, mesmo em boas condições, são jogados fora. A criação dos Bancos de Alimentos é uma forma de aproveitamento dessas sobras, atuando no recolhimento e distribuição a associações beneficentes ou diretamente a famílias carentes. Iniciativas como essa funcionam em São Paulo (Programa Mesa São Paulo, do Sesc, e na Prefeitura de Santo André, por exemplo) e em várias outras capitais.

Aumento da Oferta de Alimentos Básicos - A implantação conjunta dos programas de melhoria na renda, barateamento da alimentação e das ações emergenciais irá, certamente, aumentar muito a demanda por alimentos no País. Nesse caso, serão necessários programas de estímulo aos agricultores familiares, através do redirecionamento de créditos agrícolas, do incentivo à agricultura urbana com programas de zoneamento que permitam aproveitar terrenos para implantação de hortas. Através da criação de canais de venda dos produtos, compras institucionais (merenda, hospitais, presídios e programas do cupom-alimentação) e parceiras com supermercados (estímulo a compras de produtores locais), pode-se incentivar o acesso dos agricultores familiares aos mercados locais.

\section{CONSIDERAÇÕES FINAIS}

Mostramos, neste texto, que o problema da fome permanece grave no País e está hoje fortemente relacionado com a falta de renda para uma alimentação adequada, em função dos baixos salários e do desemprego crescente nas regiões metropolitanas, sem deixar de lado a falta de canais de abastecimento locais (como nas regiões da seca do Nordeste).

Analisando em retrospecto as políticas alimentares no Brasil, foi possível observar como elas mudaram de caráter ao longo das décadas. De forma bastante simplificada, as políticas alimentares foram analisadas a partir dos seguintes períodos: no início do século passado, predominaram políticas de intervenção para resolver o problema dos preços altos e da falta de alimentos. A partir dos anos 30 , predominou a visão de atuar nas estruturas de distribuição. Ampla estrutura de estocagem e distribuição de alimentos foi criada nacionalmente, sobretudo a partir da década de 60. Em seguida, nos anos 70, ampliou-se a intervenção pública e o Estado passou a atuar no incentivo à produção agropecuária, gestão direta das estruturas de comercialização e na regulação do mercado. Finalmente, no final dos anos 80 , observou-se o desmonte das políticas agrícolas - em particular a do crédito rural subsidiado - que deram sustentação à agricultura intensiva, embora a produtividade e a produção continuassem a elevar-se nas décadas seguintes, e das políticas de abastecimento.

Os anos 90 foram marcados por dois períodos muito distintos: na primeira metade da década, houve grande mobilização da sociedade em torno do tema do combate à fome e à miséria, resultando na formação, pela primeira vez, de uma institucionalidade integrada, de caráter nacional, para o combate à fome. Essa estrutura dinamizadora, o Consea, teve, no entanto, vida curta. A segunda metade da década foi marcada pelo desmonte das estruturas anteriores e sua substituição por políticas focalizadas, de articulação com as comunidades, e pelo fornecimento de programas de renda mínima do tipo bolsa-escola, bolsa-saúde, etc.

Considerando-se as oscilações recentes da economia brasileira e o fato de que essas propostas ainda estão em fase de implantação, pouco há para se avaliar. No entanto, o texto também mostrou uma série de iniciativas, algumas já em andamento, outras novas que, se implantadas de forma integrada, serão capazes de reduzir enormemente o problema da fome no País, envolvendo toda a sociedade.

\section{NOTAS}

E-mail dos autores: belik@eco.unicamp.br,graziano@eco.unicamp.br e mayatakagi@hotmail.com

Esse texto faz parte do Projeto Fome Zero que está sendo elaborado pelo Instituto Cidadania (www.icidadania.org.br).

1. Os indigentes são calculados através da quantificação de pessoas ou famílias com renda abaixo do necessário para adquirir uma cesta de alimentos com quantidades energéticas mínimas ou recomendadas. A linha de pobreza é superior à de indigência pois inclui, além do valor dos alimentos, outras despesas não alimentares, como vestuário, moradia, transportes, etc.

2. Del Grossi, Graziano da Silva e Takagi (2001) calcularam o crescimento das pessoas pobres entre 1995 e 1999, chegando à taxa de 1,2\% ao ano, bastante próxima da taxa vegetativa de crescimento da população brasileira. No entanto, nas regiões metropolitanas, a taxa de crescimento foi de 5,0\% a.a., enquanto nas áreas urbanas não metropolitanas e nas áreas rurais foram de, respectivamente, $0,9 \%$ e $-0,4 \%$ a.a.

3. É importante mencionar que, na década de 90 , com a liberalização dos mercados, os preços alimentares no atacado continuaram a suplantar 
o IPA-DI total. O IPA-DI de gêneros alimentícios subiu 230,2\% ao ano, contra $205,7 \%$ do IPA-DI geral. Durante todo o período, no entanto, verifica-se que os preços recebidos pelos produtores agrícolas são decrescentes.

4. No Brasil, assim como em outros países, o crescimento da comercialização de alimentos em supermercados está diretamente ligado ao seu processamento. A venda em supermercados exige embalagens homogêneas e pesos e dimensões previamente estabelecidos. Só recentemente é que a tecnologia proporcionada pela informática permitiu que as grandes instalações de varejo pudessem comercializar vantajosamente produtos a granel.

5. Percebe-se a partir do fim da década passada uma ação mais coordenada em torno de programas de "Combate à Pobreza" (Banco Mundial, 2000 e PNUD, 2000) ou "Segurança Alimentar" (FAO, 2000).

6. Conforme dados presentes em www.mec.gov.br (julho 2000).

7. A respeito dos resultados e do diagnóstico das causas da fome, ver a versão preliminar para discussão do Projeto Fome Zero (www.icidadania.org.br).

8. Nos EUA, as avaliações dos programas de combate à fome mostram que o mais eficiente é o food stamps, que garante o acesso à compra de alimentos através de selos (cupons): para cada dólar recebido, as famílias aumentam seus gastos com alimentos de $17 \%$ a $47 \%$, com uma média de $30 \%$. Outros programas que, ao invés de cupons, distribuem dinheiro (tipo renda mínima ou bolsa-escola, por exemplo) têm impacto bem menor: de cada dólar recebido em dinheiro, as famílias pobres aumentam o consumo de alimentos entre $5 \%$ e $11 \%$ no máximo, "desviando" a maior parte dos recursos para o pagamento de outras despesas. Ver, a respeito, Rossi (1998).

\section{REFERÊNCIAS BIBLIOGRÁFICAS}

AZEVEDO, E. et alii. "Eficácia de bolsa-escola depende de manter renda". Gazeta Mercantil, 17/04/01.

BAER, W.A. Economia brasileira. São Paulo, Nobel, 1995.

BANCO MUNDIAL. Relatório sobre o desenvolvimento mundial 2000/ 2001 - Luta contra a Pobreza, 2000.

BURNIER, D. Agricultura brasileira: a produção de alimentos. Tese de doutorado. São Paulo, FFLCH/USP, 2000.

CAMARGO, J.M. e FERREIRA, F.H.G. "O benefício social único: uma proposta de reforma da política social no Brasil", jan. 2001, mimeo.

COHN, A. "Políticas sociais e pobreza no Brasil." Planejamento e Políticas Públicas. Ipea, n.12, jan./dez. 1995, p.1-17.

DEL GROSSI, M.; GRAZIANO DA SILVA, J. e TAKAGI, M. "Evolução da pobreza no Brasil, 1995-99". Texto a ser apresentado no Congresso Anual da Anpec, dez. 2001, mimeo.

DIAS, G. et alii. "Reestruturação do sistema financeiro - agricultura projeto, 2000”. Comif, 2000, mimeo.
FAO - Food and Agriculture Organization. The sixth food survey, 1996. . The state of food insecurity in the world (SOFI), 2000.

FERREIRA, F.H.G.; LANJOUW, P. e NÉRI, M. "A new poverty profile for Brazil, using PPV, PNAD and Census Data". Texto para discussão, n.418. Rio de Janeiro, PUC-Rio/Departamento de Economia, 2000.

FRITSCH, W. “Apogeu e crise da primeira república: 1900-1930”. In: ABREU, M.P. (org.). A ordem do progresso: cem anos de política econômica republicana (1889-1989). Rio de Janeiro, Campus, 1990.

GASQUES, J.G. "Gastos públicos na agricultura". Texto para discussão. Brasília, Ipea, n.782, 2001.

GUERRA, A. e CAZZUNI, D.H. "O comportamento do programa de alimentação do trabalhador no Brasil durante os anos 90”, 2001, mimeo.

HENRIQUES, R. Desigualdade e pobreza no Brasil. Rio de Janeiro, Ipea, 2000.

HOFFMANN, R. "A distribuição de renda no Brasil no período $1993-$ 99", 2001, mimeo.

LAVINAS, L. et alii. Combinando o compensatório e o redistributivo: o desafio das políticas sociais no Brasil. Rio de Janeiro, Ipea (Texto para discussão, 748).

LOBATO, A.L. "Critérios de combate à pobreza e à desigualdade". Gazeta Mercantil, 06/02/01.

MALUF, R. "Consumo de alimentos no Brasil: traços gerais e ações públicas de segurança alimentar”. Série Papers n.6. São Paulo, Pólis, 2000.

PNUD - Programa das Nações Unidas para o Desenvolvimento. We the people - the role of the United Nations in the 21st century, 2000 (www.undp.org.br).

ROCHA, S. "Pobreza no Brasil. O que há de novo no limiar do século XXI?", set. 2000, mimeo.

ROSSI, P. Feeding the poor: assessing federal food aid. Washington, The AEI Press, 1998.

SECRETARIA DE AGRICULTURA E ABASTECIMENTO. Conjuntura Alimentos. São Paulo, Coordenadoria de Abastecimento, mar. 1986.

TAKAGI, M.; GRAZIANO DA SILVA, J. e DEL GROSSI, M. "Pobreza e fome: em busca de uma metodologia para quantificação do problema no Brasil". Texto para discussão, n.101. Campinas, IE/Unicamp, 2001.

TERRA, O. "Comunidade ativa". Cadernos da Oficina Social, n.5. Rio de Janeiro, 2000.

VALENTE, F. "O combate à fome e à desnutrição e a promoção da alimentação adequada no contexto do Direito Humano à Alimentação - um eixo estratégico do desenvolvimento humano sustentável”, 2001, mimeo. 